\title{
Chile y la OCDE. \\ La dicotomia entre lo macroeconómico y el desarrollo humano*
}

\section{Chile and the OECD. A dichotomy between macroeconomic results and human development}

\author{
Luis A. Riveros Cornejo** \\ Gustavo A. Báez Castillo***
}

\section{Resumen}

La economía de Chile ha mostrado singular fortaleza desde la década de 1990. El establecimiento de una trayectoria de alto crecimiento económico e inversión, el aumento del ingreso per cápita, la inflación bien contenida y los excedentes fiscales han sido hechos recurrentes. Sin embargo, persiste una preocupante dicotomía entre los buenos resultados macroeconómicos y lo limitado de aquellos relativos a las variables humanas subyacentes, especialmente en educación, salud e innovación, lo cual permite otorgar baja sustentabilidad a los resultados en cuanto a competitividad internacional y estabilidad macroeconómica. Este trabajo pone de relieve ese contraste, basado en la información comparativa disponible del Foro Económico Mundial.

Palabras clave: Chile, OCDE, estabilidad macroeconómica, desarrollo humano.

Los autores agradecen los comentarios de participantes en un Seminario del Centro Asia - Pacífico, como asimismo de un referee anónimo de la revista Estudios Internacionales

** Profesor titular, Facultad de Economía y Negocios e Instituto de Estudios Internacionales, Universidad de Chile.<lriveros@fen.uchile.cl>

**: Docente de Lógica y Metodología de la investigación, Facultad de Economía y Negocios, Universidad de Chile.gbaezc@fen.uchile.cl.

Recibido el 8 de agosto de 2014;aceptado el 2 de octubre de 2014. 


\section{Abstract}

The Chilean economy has exhibited a noticeable performance since the 1990s. High economic growth and investment, the sustained increase in per capita GDP, low inflation and the existence of fiscal surpluses have been repeated results along past decades. However, there prevails a worrisome dichotomy between positive macroeconomic results and poor indicators relative to the human dimension, particularly education, health and innovation, a situation that originates doubts as to the sustainability of economic results, particularly in terms of international competitiveness and macroeconomic stability. This paper illustrates the situation using comparative information available from the World Economic Forum.

Keywords: Chile, OECD, macroeconomic results, human development 
Luis A. Riveros y Gustavo A, BÁez • Chile y la OCDE. Dicotomía entre lo...

\section{INTRODUCCIÓN}

La revisión de diversos indicadores que comparan a Chile con los países miembros de la Organización para la Cooperación y el Desarrollo Económico (OCDE) da cuenta del contraste en cuanto a resultados económicos agregados y aquellos que reflejan las condiciones humanas que subyacen a los mismos. La comparación revela la profunda brecha existente en Chile entre los resultados de tipo macroeconómico y aquellos referidos al capital humano. En efecto, los indicadores macroeconómicos posicionan a Chile como un país del primer mundo, mientras que los indicadores de desarrollo humano más básicos muestran un país típicamente subdesarrollado. Esta contradicción está en la raíz misma del descontento social, ya que sin correcciones este desbalance llevará a profundizar esta notoria segmentación.

El concepto de lo macroeconómico que preocupa a este trabajo tiene que ver con algunos aspectos específicos relativos al desenvolvimiento de un país. Nos referimos especialmente a la estabilidad macroeconómica, que descansa fundamentalmente en aspectos de crecimiento, ingreso per cápita, inflación y estabilidad de precios relativos. Todo ello conforma el llamado "ambiente para la inversión”. Al mismo tiempo, esos aspectos macroeconómicos tienen que ver con la competitividad de la economía, esto es la capacidad para competir internacionalmente en materias de comercio internacional y atractivo para la inversión. Esta dimensión macroeconómica es la que contradice, muchas veces, aquellos otros elementos referidos al desarrollo humano, y que tienen que ver con calidad de vida, como es la distribución del ingreso nacional, los resultados en materias de educación, capacitación y salud, además de otros relativos a medio ambiente, innovación y oportunidades para la población.

El desarrollo integral de una economía debe resultar de una conjunción de variables donde ciertos factores de base, vinculados al capital humano, potencian la sostenibilidad del crecimiento y la estabilidad de los equilibrios macroeconómicos. Cuando se habla de capital humano, se está refiriendo a variables que directamente se relacionan con las personas y las condiciones para su mejor desenvolvimiento presente y futuro como es el caso de la educación, la salud y la investigación, desarrollo e innovación $(\mathrm{R}+\mathrm{D}+\mathrm{i})$. Esta última la consideramos una variable en la dimensión del desarrollo humano puesto que permite el mejor uso de los recursos para alcanzar, precisamente, una mejor realización de las personas en la actividad productiva como en la propia dimensión de educación y salud. Ciertamente hay muchos otros aspectos como la previsión social, las oportunidades de realización económica y social, el medio ambiente en que se desenvuelven, y otros, que son también de gran importancia pero de mucha más escasa o difícil cuantificación en términos comparativos internacionales. 
La inserción estratégica de Chile en la arquitectura internacional ha facilitado el intercambio comercial y la cooperación en distintos ámbitos, integrando a nuestro país a una red global que ha brindado oportunidades y desafíos en su proceso de desarrollo. En efecto, la inserción de Chile en la economía global ha incrementado las posibilidades de distintas áreas productivas y regiones del país. Esto mismo no ha dado lugar a la inversión en ámbitos que, como educación, salud y R\&D+I, son factores subyacentes a los resultados económicos futuros. La pregunta que surge a partir de la comparación propuesta en este trabajo es si Chile está o no haciendo lo suficiente para cerrar la brecha entre sus auspiciosos resultados macroeconómicos y aquellos relativos a los factores humanos subyacentes.
II. Chile- OCDE. UnA

COMPARACIÓN EN EL ÁMBITO MACROECONÓMICO

Chile detenta un bien ganado prestigio como "jaguar latinoamericano", con indicadores económicos de nivel OCDE en varios aspectos de su macroeconomía, destacando también por su reconocida estabilidad económica y política. De hecho, su nivel de ingreso per cápita lo coloca a las puertas del "club" de los países desarrollados, esto a pesar de que se entiende que el estatus del "desarrollo" integra factores más complejos que el simple indicador de "producto por habitante". A pesar de ello el tránsito chileno de los últimos años en esta materia ha sido impresionante (Gráfico $\mathrm{N}^{\circ} 1$ ).

\section{Gráfico N ${ }^{\circ}$ 1.CHILE: PIB per cápita real (US\$)}

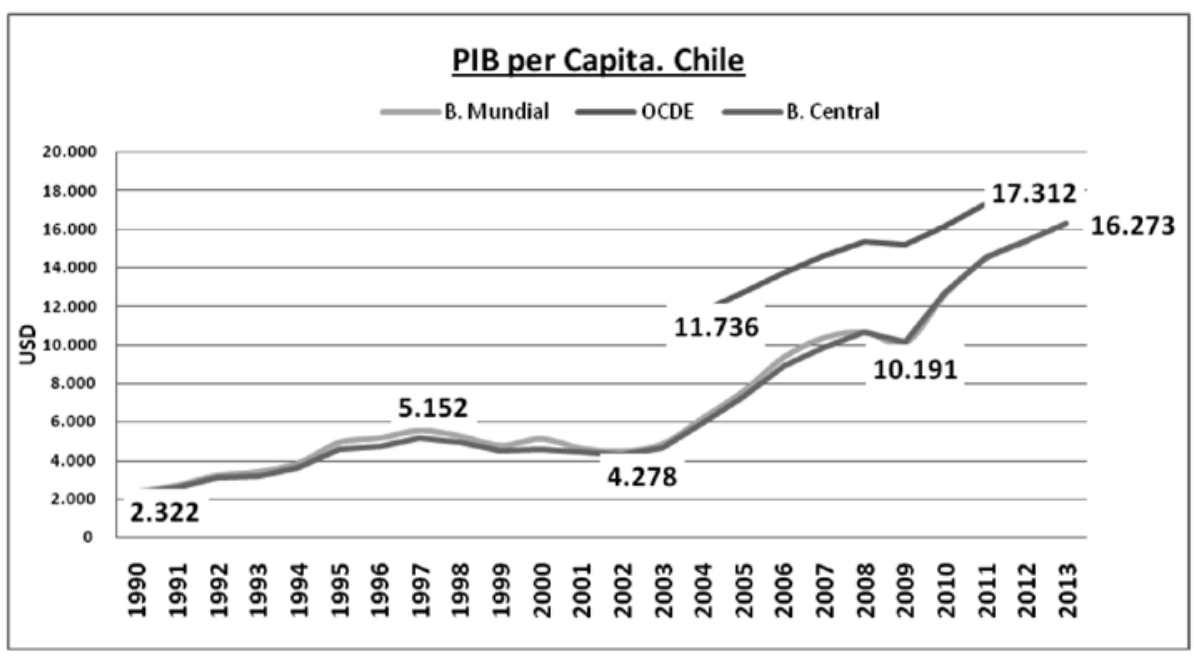

Fuente: Banco Central de Chile. Banco Mundial. OCDE. 
Luis A. Riveros y Gustavo A, BÁez • Chile y la OCDE. Dicotomía entre lo...

La solidez de la economía chilena y la gestión macroeconómica se indican como efectivos protectores frente a la recesión económica mundial ${ }^{1}$ iniciada el año 2008 y que extendiera un largo periodo de incertidumbre económica mundial, afectando a los mercados internacionales por la vía del deterioro de los términos de intercambio del comercio mundial. Chile como economía pequeña y abierta, dependiente de las exportaciones -especialmente cobrefue duramente golpeada por esa crisis financiera y la caída conexa de los precios de los commodities, lo cual tuvo efectos negativos en la demanda interna y la actividad. En este marco, el gobierno implementó con rapidez políticas anticíclicas y con la ayuda de un rebote de los precios del cobre durante el año 2009, la economía chilena salió de la desaceleración. Asimismo, respecto de la reciente crisis europea, esta tampoco ha tenido un efecto demasiado negativo en el crecimiento chileno pese al menor dinamismo del crecimiento mundial y el aparente término de la bonanza de los precios del cobre. El crecimiento económico posterior a 2009 se ha mantenido alto y así lo ha hecho también el producto per cápita.

1 Economic Survey of Chile. Policy Brief. Organisation for Economic Co-operation and Development. January 2010. El informe presenta la evaluación de políticas y recomendaciones de la Encuesta de 2010 de la OCDE. El comité se compone de los 30 países miembros y la Comisión Europea, que se celebró un seminario especial para discutir este estudio con la participación del gobierno chileno.
Aunque Chile no es inmune a las fluctuaciones económicas internacionales, su economía ha destacado por un buen desempeño en periodos de crisis, exhibiendo una trayectoria de crecimiento vigorosa ${ }^{2}$. La última medición del Índice de Competitividad Global ${ }^{3}$ del Foro Económico Mundial, con datos válidos para el periodo 2012-2013, sitúa a Chile en un destacable lugar $\mathrm{N}^{\circ}$ 33 de un universo de más de 140 países (Gráfico $\mathrm{N}^{\circ} 2$ ), cercano al promedio de los países OCDE (promedio destacado en verde).

2 Banco Central de Chile. Base de Datos Estadísticos. Cuenta Nacionales. Revisión en línea de indicadores estadísticos de la base de datos. Disponible en http://si3. bcentral.cl/Siete/secure/cuadros/home. aspx.

3 The Global Competitiveness Report 2012-20013:la Full Data Edition es publicada por el World Economic Forum dentro del marco de The Global Benchmarking Network. Profesor Klaus Schwab Director Ejecutivo, Profesor Xavier Salai-Martín, Consultor Principal de la Global Benchmarking Network. Børge Brende, Director Administrativo de Relaciones con los gobiernos y participación de los miembros, Foro Económico Mundial. Ginebra. Copyright (C) 2012. by the World Economic Forum. ISBN-13: 978-92-95044-35-7. ISBN-10: 92-95044-35-5. 
Gráfico $N^{\circ}$ 2. Chile-OCDE en el Índice de Competitividad Global

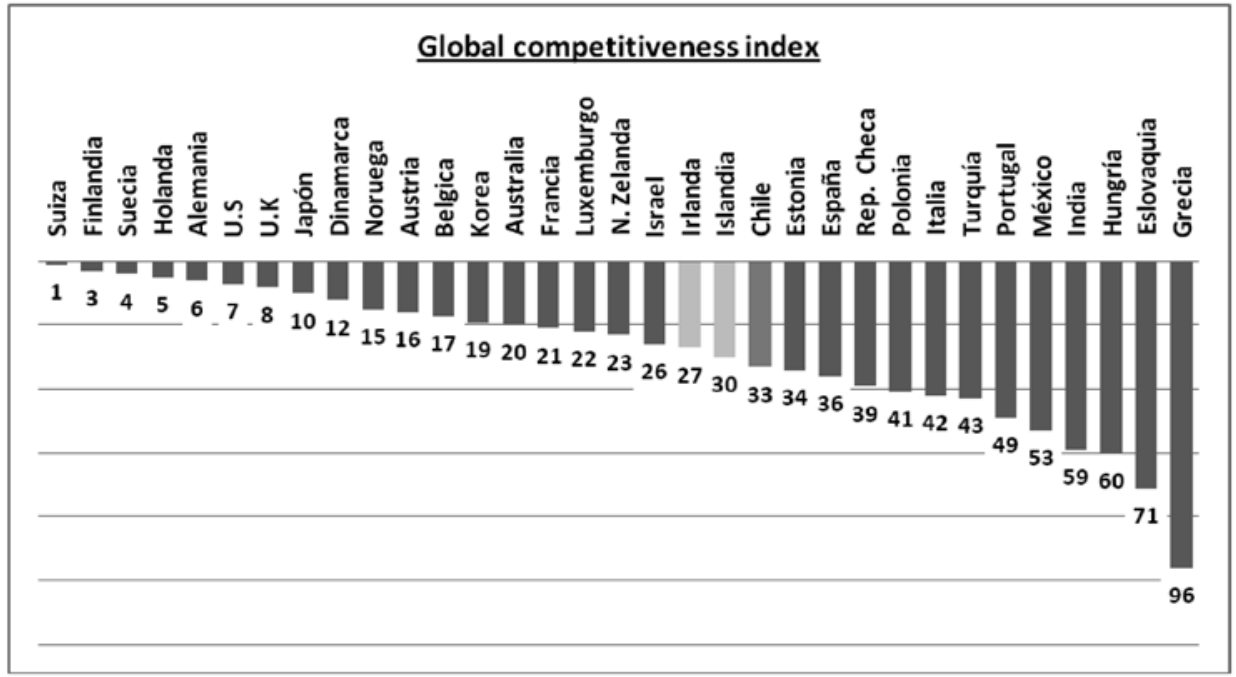

Fuente: Elaboración propia, a partir de la serie de datos del FEM.

El Índice de Competitividad Global ${ }^{4}$ (ICG) reúne doce variables de análisis que el Foro Económico Mundial organiza en tres grupos. Un primer grupo es el relativo a los requisitos básicos, que comprende i) estabilidad macroeconómica, ii) calidad de las instituciones, iii) infraestructura social, y $i v$ ) provisión de educación primaria y salud. Un segundo grupo de factores que determinan la competitividad de la economía se refiere a aspectos como $v$ ) calidad de la educación superior, $v i$ ) eficiencia del

4 El Foro Económico Mundial define el concepto de competitividad en torno a doce pilares; Instituciones, Infraestructura, estabilidad macroeconómica, salud y educación primaria, educación superior, eficiencia del mercado de bienes y servicios, eficiencia del mercado del trabajo, sofisticación del mercado financiero, preparación tecnológica, tamaño del mercado, sofisticación de los negocios, Innovación. mercado de bienes, vii) eficiencia del mercado del trabajo, viii) sofisticación del mercado financiero, $i x$ ) preparación tecnológica y $x$ ) tamaño de mercado. En último término, se adiciona un tercer grupo de variables que se relacionan con aquellos factores que potencian la innovación en una economía, a saber: xi) sofisticación de los negocios y por último xii) innovación.

Los resultados en materia de competitividad para Chile se asocian fundamentalmente a variables de tipo macroeconómico, en especial estabilidad macroeconómica y calidad de las instituciones, además de eficiencia de los mercados y sofisticación del mercado financiero. En efecto, el Foro Económico Mundial destaca la estabilidad en el desempeño de la economía chilena, señalándola reiteradamente como la economía más competitiva de América 
Luis A. Riveros y Gustavo A, Báez • Chile y la OCDE. Dicotomía entre lo...

Latina, con un vigoroso crecimiento y solidez de las políticas macroeconómicas, lo cual posiciona al país en una destacable posición $\mathrm{N}^{\circ} 14$ en el ranking de 144 países considerados en el Índice de Competitividad Global (ICG).

Siguiendo el mismo Indice de Competitividad, analizado según variables, se observan resultados positivos en diversos ámbitos: los niveles de deuda pública de Chile son bastante bajos y lo sitúan en el lugar $10^{\circ}$ a nivel mundial, el superávit del presupuesto público lo ubica en el lugar 21 del ranking, el funcionamiento de las instituciones públicas en el lugar 28, el desarrollo de la infraestructura en la posición 40 . En esta misma línea, las políticas de liberalización y apertura del comercio han dado lugar a mercados flexibles y eficientes que garantizan una buena asignación de los recursos en función del mercado de bienes, el mercado del trabajo y el mercado financiero.
El ambiente macroeconómico resulta importante tanto para la generación de negocios como para mejorar la competitividad de un país en su conjunto. La experiencia internacional indica que la inestabilidad macroeconómica daña a la economía, como se ha visto en los últimos años en el contexto europeo y actualmente lo evidencian algunas economías latinoamericanas. La destacada posición de Chile en materia de competitividad es un factor destacable en el contexto comparativo internacional.

Sin embargo, pese a la destacadapresencia de Chile en cuanto al ICG, es posible observar una tendencia a la baja en la competitividad de acuerdo a la serie de informes 2001-2012, como lo ilustra el gráfico $\mathrm{N}^{\circ} 3$. Esta es una señal de alerta puesto que la disminución de la competitividad afecta la capacidad de respuesta de la economía frente a requerimientos impuestos en un escenario de crisis.

\section{Gráfico $N^{o}$ 3. Evolución del indice de Competitividad Global}

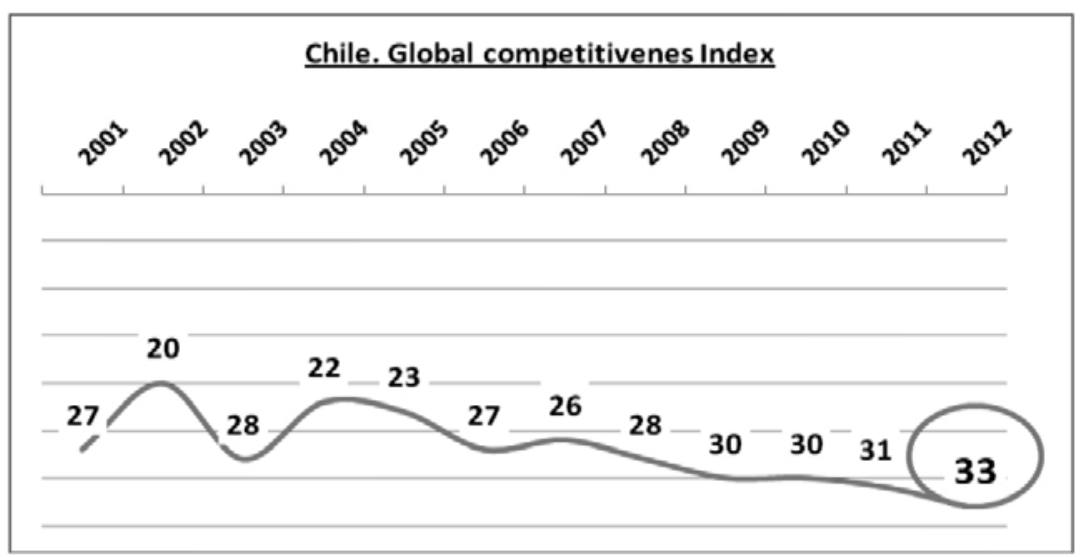

Fuente: Elaboración propia, a partir de la serie de datos del FEM. 
En lo que respecta a los resultados macroeconómicos, tal como se mencionó, los datos comparativos economía no podría crecer de manera sostenida sin un ambiente macroeconómico estable.

Gráfico $N^{\circ}$ 4. Chile-OCDE. Estabilidad Macroeconómica.

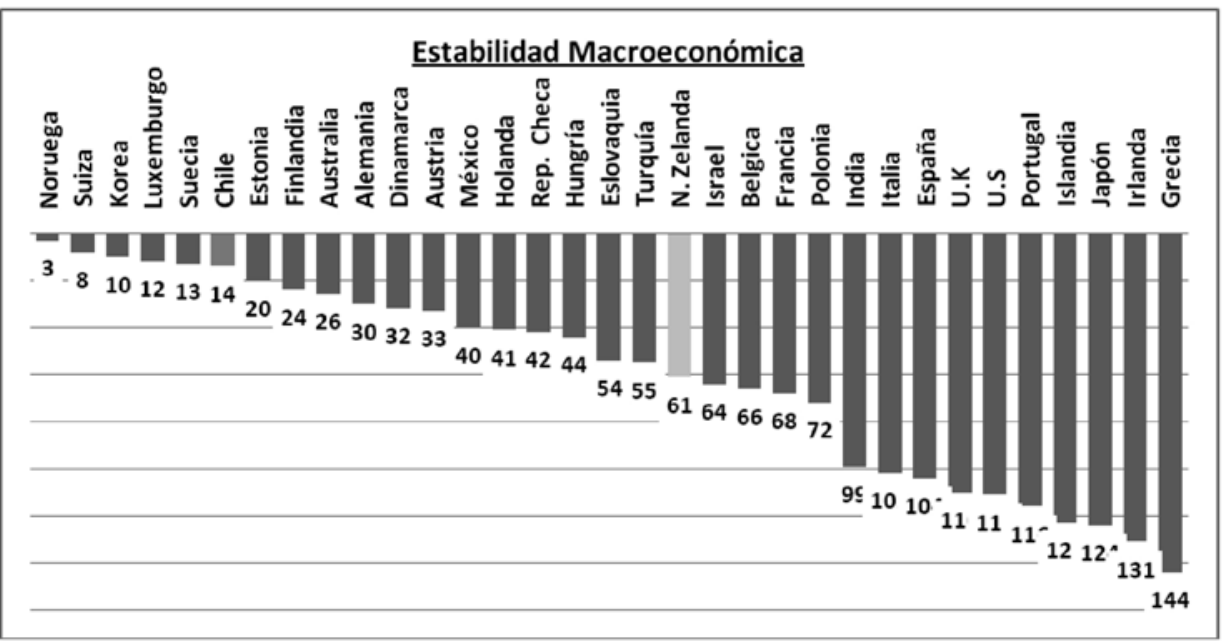

Fuente: Elaboración propia, a partir de la serie de datos del FEM.

ponen a Chile en el lugar 14 entre 144 economías $^{5}$ (Gráfico $N^{\circ} 4$ ). Este indicador agrupa a variables tradicionales sobre crecimiento económico: inflación, déficit público, ahorro y tasas de inversión agregadas, etc. Un buen desempeño macroeconómico permite a un país proveer servicios eficientemente y entregar señales adecuadas a los agentes económicos, facilitando la inversión y el crecimiento. Del mismo modo, un déficit fiscal acotado permite a los gobiernos reaccionar frente a los ciclos económicos $\mathrm{y}$, adicionalmente, evitar un aumento de la inflación. En consecuencia, la

5 The Global Competitiveness Report 2012-20013. Op. Cit.
En suma, de conformidad con los antecedentes anteriores se observa que Chile ha logrado una sólida base en materia de competitividad internacional y en estabilidad macroeconómica, factores cruciales para atraer inversión extranjera. De acuerdo con esto, es posible destacar que la función de producción de la economía chilena ha tenido un desempeño destacable en lo que respecta a las variables agrupadas en el pilar llamado requisitos básicos. Tal como lo muestra el gráfico $\mathrm{N}^{0} 5$, en este primer grupo de indicadores se sitúa por encima del promedio $^{6}$ de la OCDE.

6 El Primer grupo de factores relativo a los requisitos básicos se compone de las si- 
Luis A. Riveros y Gustavo A, BÁez • Chile y la OCDE. Dicotomía entre lo...

Gráfico $N^{\circ}$ 5. Chile-OCDE. Requisitos básicos de desarrollo.

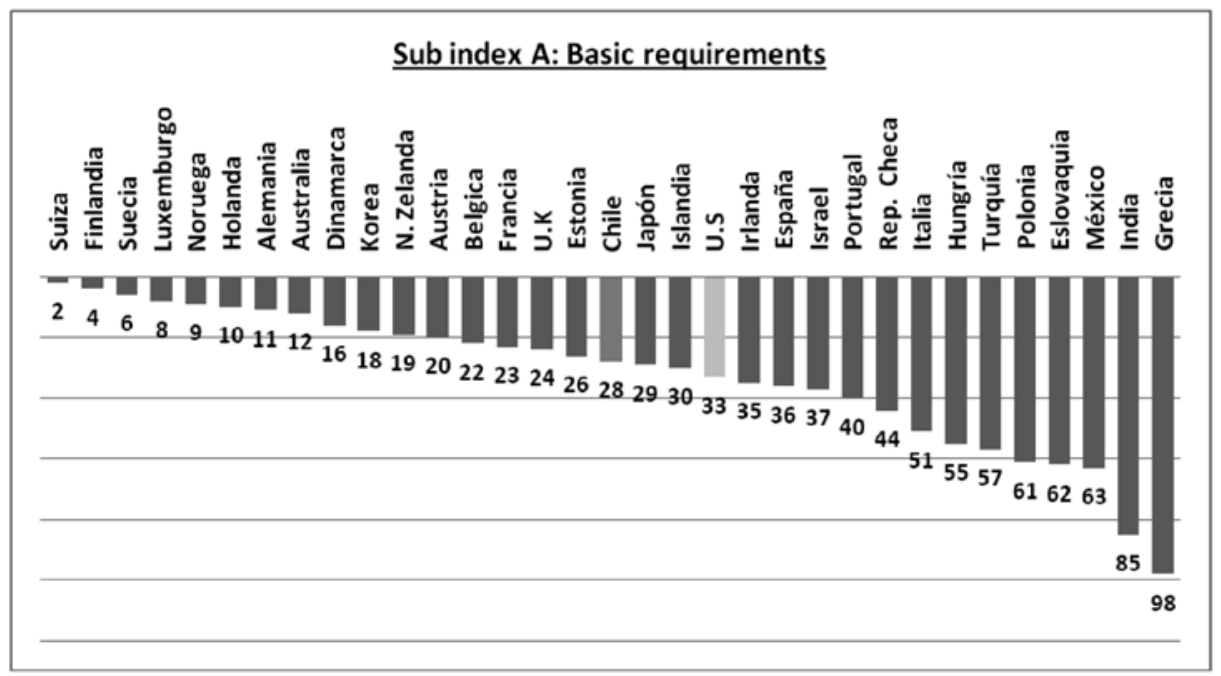

Fuente: Elaboración propia, a partir de la serie de datos del FEM.

\section{III.CHILE - OCDE: FACTORES} DE BASE PARA EL DESARROLLO

A pesar de lo anterior, nuestro país muestra resultados modestos en un grupo de factores que determinan la eficiencia y la equidad social como ya lo destacara una serie de informes realizados por la OCDE en los años 20047,

guientes variables: 1. Estabilidad macroeconómica. 2. Instituciones. 3. Infraestructura. 4. Salud y educación primaria.

7 Revisión de Políticas nacionales de Educación. La educación superior en Chile. OCDE y el Banco Internacional para la reconstrucción y el desarrollo. Banco Mundial y, Ministerio de Educación. 2009.
2009 ${ }^{8}, 2013^{9}$. Al parecer, en Chile la tarea en materia de distribución del ingreso, salud y educación está lejos de haberse completado satisfactoriamente, lo que revela el contraste entre el destacable desempeño de los datos macroeconómicos y los resultados aún modestos en áreas clave para el desarrollo de largo plazo. Es necesario subrayar que estos aspectos no pueden considerarse "residuales" ni desvinculados del comportamiento agregado de la economía. Por el contrario, el Foro Económico

8 Revisión de Políticas nacionales de Educación. Chile. Centro para la cooperación con los países no miembros de la OCDE. Organización para la cooperación y el desarrollo económicos OCDE. Publicado por acuerdo con la OCDE Paris y el Ministerio de Educación de Chile 2004.

9 Revisión de Políticas Nacionales de Educación. El aseguramiento de la calidad en educación superior en Chile 2013. 
Mundial considera que son requisitos previos para el mantenimiento de un estándar macroeconómico adecuado y contrastando así marcadamente con los resultados macroeconómicos.

\section{Gráfico $N^{o}$ 6. Posición relativa Chile-OCDE en salud y formación de capital humano básico.}

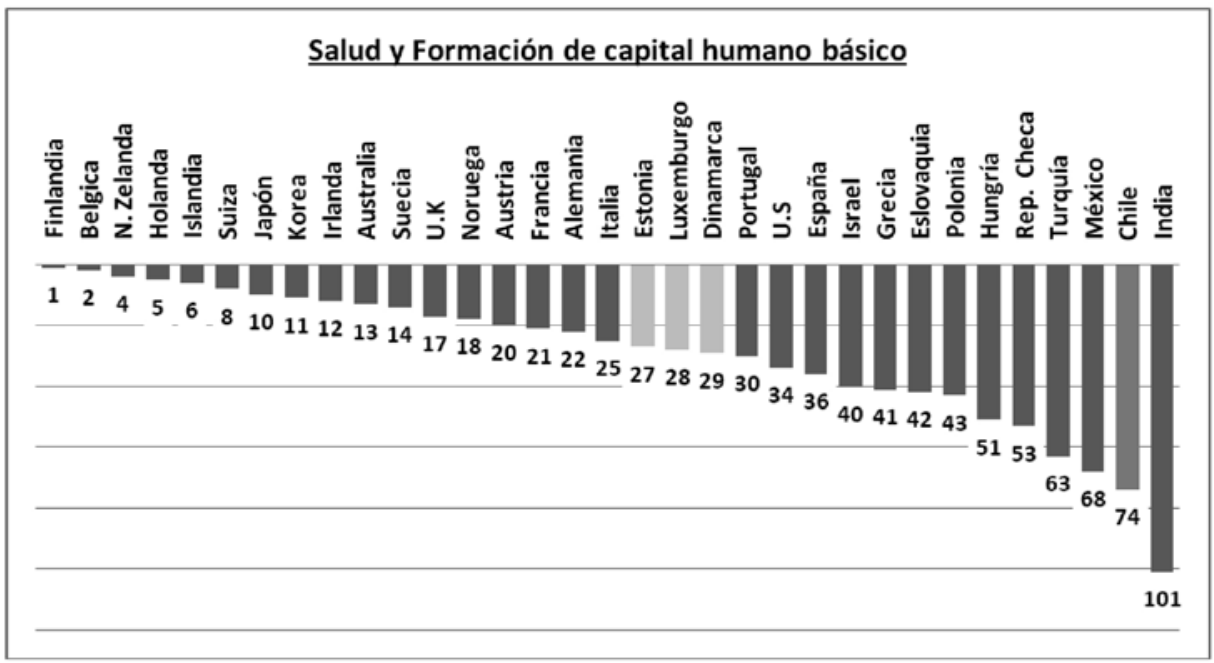

Fuente: Elaboración propia, a partir de la serie de datos del FEM.

un buen comportamiento agregado de la economía. Más aún, deben considerarse factores básicos para sostener el crecimiento a largo plazo, junto con la competitividad internacional.

El contraste que se observa en Chile entre los indicadores relativos a formación de capital humano básico y salud y los indicadores puramente económicos es manifiesto y preocupante. En esta materia, que es central desde el punto de vista de la dimensión humana del crecimiento, Chile se encuentra en una posición muy retrasada respecto del promedio de los países OCDE, ubicándose en el lugar 74 (Gráfico $\mathrm{N}^{\circ}$ 6),
Gráfico $\mathrm{N}^{\circ}$ 6. Posición relativa Chile-OCDE en salud y formación de capital humano básico.

Fuente: Elaboración propia, a partir de la serie de datos del FEM.

Pero además, las cifras muestran que Chile ha venido cayendo sistemáticamente en materia de salud y formación de capital humano básico ya que al situarse en la posición 74 , retrocedió tres puntos respecto de la medición anterior, y 17 puntos respecto del año 2006, como lo muestra el gráfico $\mathrm{N}^{\circ} 6$. Es decir, se produce el gran contrasentido de un país que figura en el lugar número 
Luis A. Riveros y Gustavo A, Báez • Chile y la OCDE. Dicotomía entre lo...

14 en el mundo en cuanto a estabilidad macroeconómica, y en el número 28 en probablemente empeorará, así deteriolo que respecta a competitividad, pero rando el medio ambiente necesario para la inversión y el crecimiento.

Gráfico $N^{o}$ 7. Salud y formación de capital humano básico.

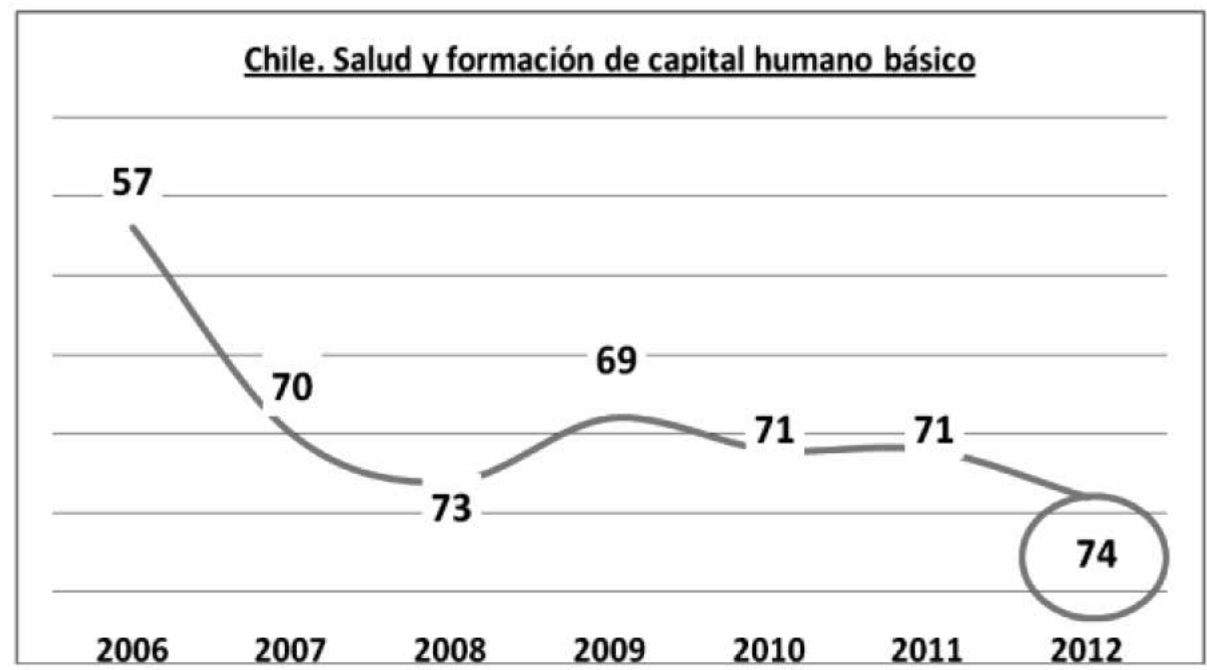

Fuente: Elaboración propia, a partir de la serie de datos del FEM.

solo en el lugar 74, con una tendencia decreciente, en cuanto a salud y educación primarias. La sostenibilidad del crecimiento y la competitividad dependen en forma central de la estabilidad social y política, que se ven amenazadas por el ambiente de disparidad e insatisfacción que señalan los factores relativos a pobre suministro en materia de factores humanos básicos. Sin ser en sí mismo indicadores distributivos (pero considerando que Chile se ubica dentro de los 15 países más desiguales del mundo) la información sobre provisión de educación y salud primarias permite sugerir que la distribución del ingreso lejos de mejorar o mantenerse,
Es decir, Chile es un país que ha retrocedido en materia de factores básicos para el desarrollo, a pesar de su significativo crecimiento en términos del ingreso per cápita. Ciertamente, estos resultados coinciden con lo que señala el informe que entrega la propia OCDE en lo relativo al gasto que Chile realiza en materia de salud y educación escolar

\section{III. a. La situación en materia de salud}

En lo relativo a salud, nuestro país muestra un gasto que está un punto porcentual por debajo del promedio 
de los países de la $\mathrm{OCDE}^{10}$. Expresado salud, a excepción de México, Estados como porcentaje del PIB, el gasto en sa- Unidos y Chile. En 2009, el 47.4\% de lud para Chile se encuentra en un $8,4 \%$, los gastos sanitarios realizados en Chile frente a un $9,4 \%$ del promedio OCDE. se financiaron con recursos públicos,

En los países OCDE el sector públi- muy por debajo del promedio de la co es la fuente principal de fondos de $\operatorname{OCDE}(71.7 \%)$.

Gráfico $N^{\circ}$ 8. Gasto en salud como proporción del PIB.

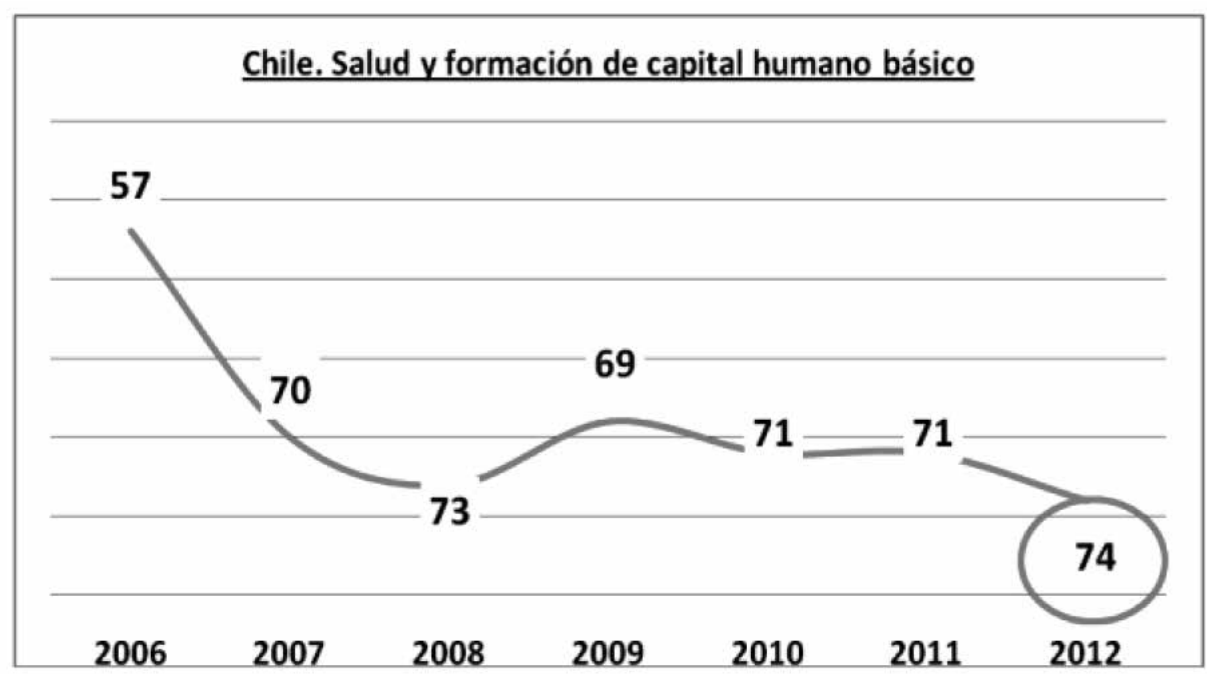

Fuente: Informe de salud OCDE 2011

10 OCD. Base de datos. Informe Salud 2011. www.oecd.org/chile. 
Luis A. Riveros y Gustavo A, BÁez • Chile y la OCDE. Dicotomía entre lo...

Gráfico $N^{\circ}$ 9. Gasto sanitario per cápita

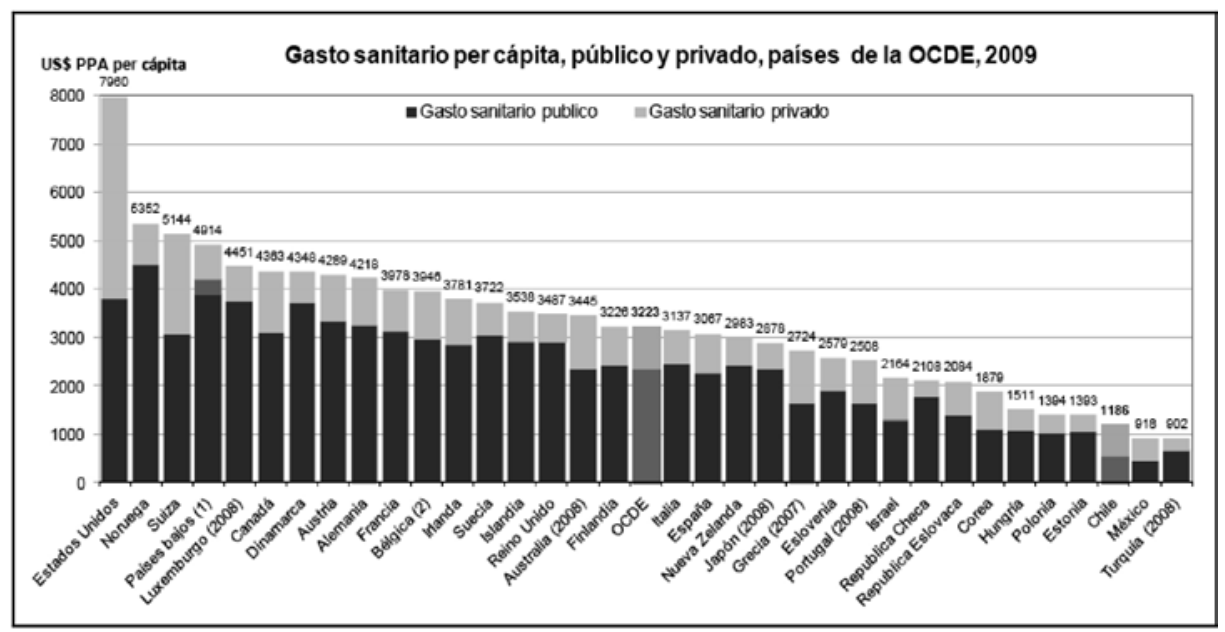

Fuente: Informe de salud OCDE 2011

Lo anterior muestra que Chile se sitúa por debajo del promedio de la OCDE en cuanto al gasto per cápita en salud, con una cifra de 1.186 dólares de los Estados Unidos en 2009 (ajustado por paridad de poder de compra); comparado con un promedio de 3.223 en los países de la OCDE. ${ }^{11}$.

\section{III. b. La situación en materia de educación}

Dentro de los factores que presentan un bajo desempeño en términos de competitividad, un segundo factor muy destacado es la calidad del sistema educativo chileno. A este respecto Chile ocupa el lugar 91 en el ranking de países (Gráfico $\mathrm{N}^{\circ} 10$ ), destacando el retraso en materia de uso de las tecnologías, aspecto en que a nivel mundial ocupamos el lugar 57.

11 OCDE. Base de datos. Informe Salud 2011. www.oecd.org/chile. 
Gráfico No 10. Chile-OCDE: Calidad del sistema educacional.

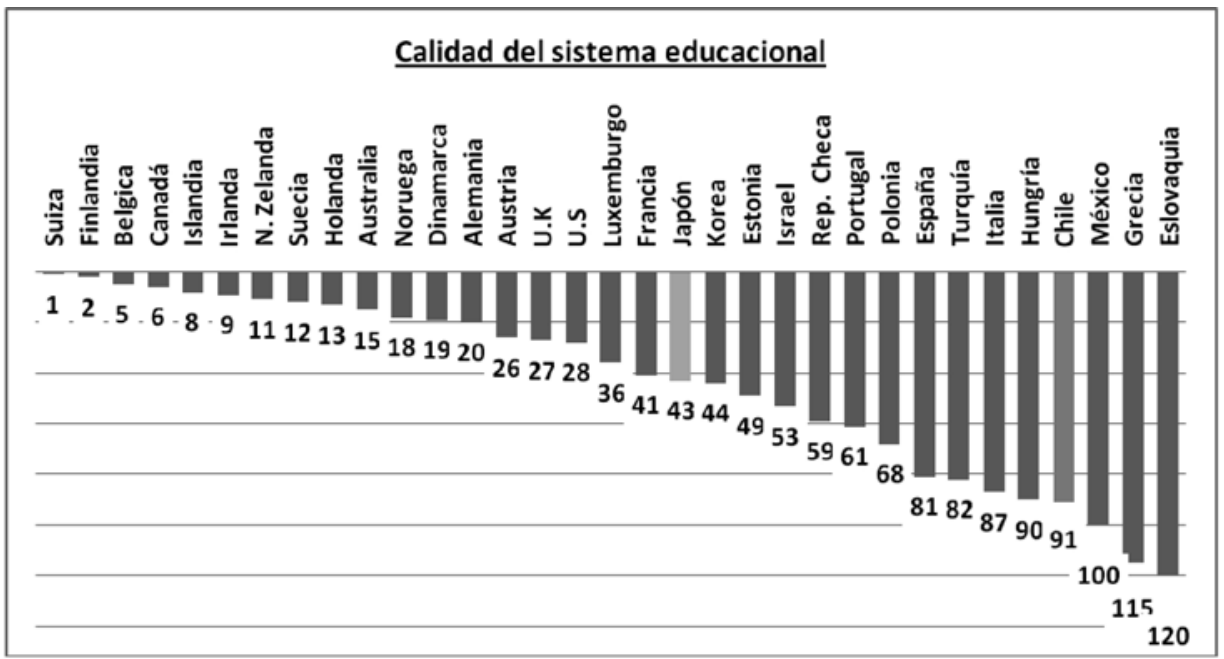

Fuente: Elaboración propia, a partir de la serie de datos del FEM.

Particularmente preocupante resulta el indicador relativo a la calidad de la educación primaria: Chile aparece en el lugar 119 del ranking. Es decir, se encuentra 80 posiciones por debajo del promedio OCDE. Lo anterior, sumado a la posición relativa que alcanza Chile en el indicador "Calidad de la educación en matemáticas y ciencias", en el cual aparece en el lugar 117 del ranking, podría explicar la insuficiente capacidad del país para generar innovación, indicador en el que aparece solo en el lugar 83 del ranking de 140 países. 
Luis A. Riveros y Gustavo A, BÁez • Chile y la OCDE. Dicotomía entre lo...

Gráfico $N^{\circ}$ 11. Chile-OCDE: Calidad de la educación en matemáticas y ciencias.

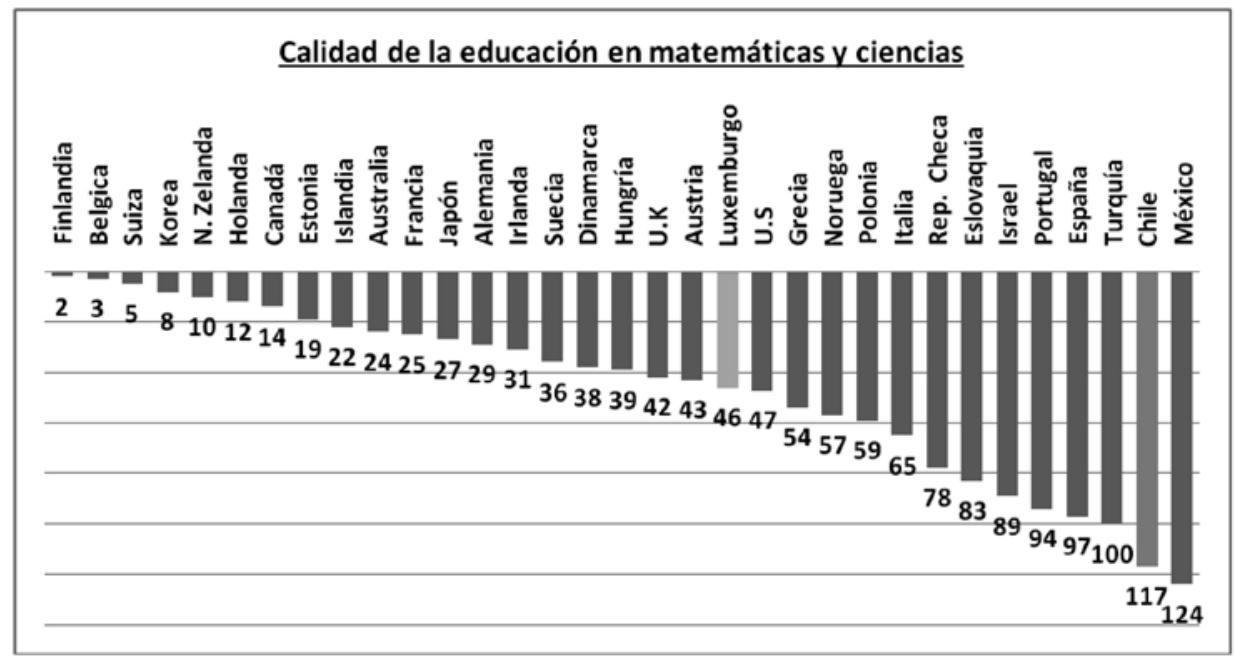

Fuente: Elaboración propia, a partir de la serie de datos del FEM.

Como lo señala el Foro Económico Mundial: "Further competitiveness gains will be contingent on successfully addressing these weaknesses. As the economy steadily moves toward a higher stage of development, many economic activities will require higher levels of skills and innovation in order to increase their competitiveness potential"12. Efectivamente, es necesario fortalecer el vínculo entre educación e innovación y la investigación. En este sentido, la innovación debe entenderse como las opciones para lograr mejor uso de los recursos existentes para privilegiar mejores resultados productivos y en factores de base como salud y educación. El reto de elevar la

12 The Global Competitiveness Report 2012-20013. Op. Cit. productividad y la competitividad de la economía depende de que se aborden con éxito estos desafíos y disminuya la brecha con los países de la OCDE. Esto es particularmente cierto en un campo como la educación, cuyos resultados son a largo plazo pero pueden optimizarse con adecuada innovación en métodos pedagógicos, modernización de los currículos y uso de la tecnología. 
Gráfico $N^{\circ}$ 12. Chile-OCDE: Calidad de la educación primaria.

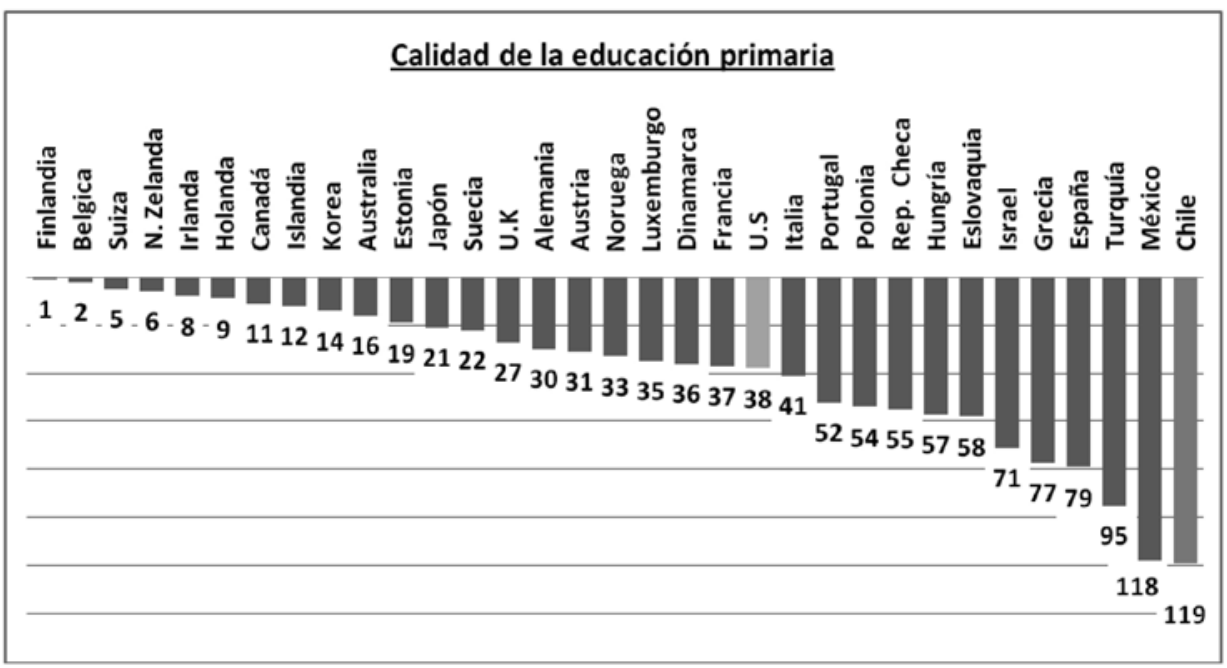

Fuente: Elaboración propia, a partir de la serie de datos del FEM.

En los aspectos relativos a Educación Primaria y Salud, entendidos como requisitos básicos de desarrollo, Chile se encuentra muy por debajo del promedio de la OCDE. A este respecto la comparación internacional sitúa a Chile por debajo del promedio APEC e incluso, en algunos casos, de América Latina, región en que, en general, prevalece un marcado retraso educativo comparado con el nivel de los países de la OCDE.

En forma consistente con lo anterior, diversos informes respecto de la calidad y la equidad de la educación primaria y secundaria en Chile aluden a su desmejorada situación. Pese a los avances en materia de cobertura escolar, aún queda mucho por hacer para que los niños chilenos alcancen los estándares de la OCDE en resultados del aprendizaje. Los informes plantean la necesidad de formar mejores docentes, aumentando su calificación como elemento clave. A estos aspectos puede agregarse la necesidad de actualizar los contenidos y currículo de la educación y de mejorar las técnicas y medios tecnológicos disponibles. Asimismo, los informes plantean la necesidad de generar condiciones más equitativas para las escuelas de modo tal que puedan competir de manera igualitaria, aun cuando el gobierno ha empezado a abordar el problema de la desigualdad del acceso con la prohibición de seleccionar alumnos hasta sexto grado. Muy en particular, como lo evidencian los datos que figuran en el Anexo, para alcanzar la situación en que se encuentran los países de la OCDE, Chile debe 
Luis A. Riveros y Gustavo A, BÁez • Chile y la OCDE. Dicotomía entre lo...

dar prioridad al incremento del gasto público en educación.

De los cuatro factores observados: instituciones, estabilidad macroeconómica, infraestructura, y salud y educación primaria, es en este último donde se observa una extrema debilidad, poniendo en riesgo lo sostenible que ha de ser el crecimiento para el desarrollo, entendido este como un concepto integral. La evaluación del potencial productivo de Chile da cuenta de un concepto de desarrollo que ha conducido a solidificar una primera generación de reformas orientadas a extender la cobertura educacional a un amplio rango de la población. La extensión en términos cuantitativos revela que la cobertura de la matrícula en los niveles primario y secundario es casi total, así como su aumento en el caso de la educación superior. Sin embargo, la calidad aún está pendiente como segunda generación de reformas, destacándose la necesidad de establecer un equilibrio entre la ampliación en términos cuantitativos del sistema educativo y la calidad de este.

Chile también muestra retrasos significativos en materia de educación superior: el país se sitúa en el lugar 46 del mundo, lejos del promedio OCDE que se encuentra en torno al 26. En este aspecto, además, el país también ha venido cayendo, lo que indica que la expansión de la educación superior no ha tenido como contrapartida un aumento, y ni siquiera el mantenimiento, de su calidad, como lo pone de relieve la sistemática caída registrada por este indicador durante los pasados seis años.

Gráfico $\mathrm{N}^{\mathrm{0}}$ 13. Chile-OCDE: Educación superior y capacitación.

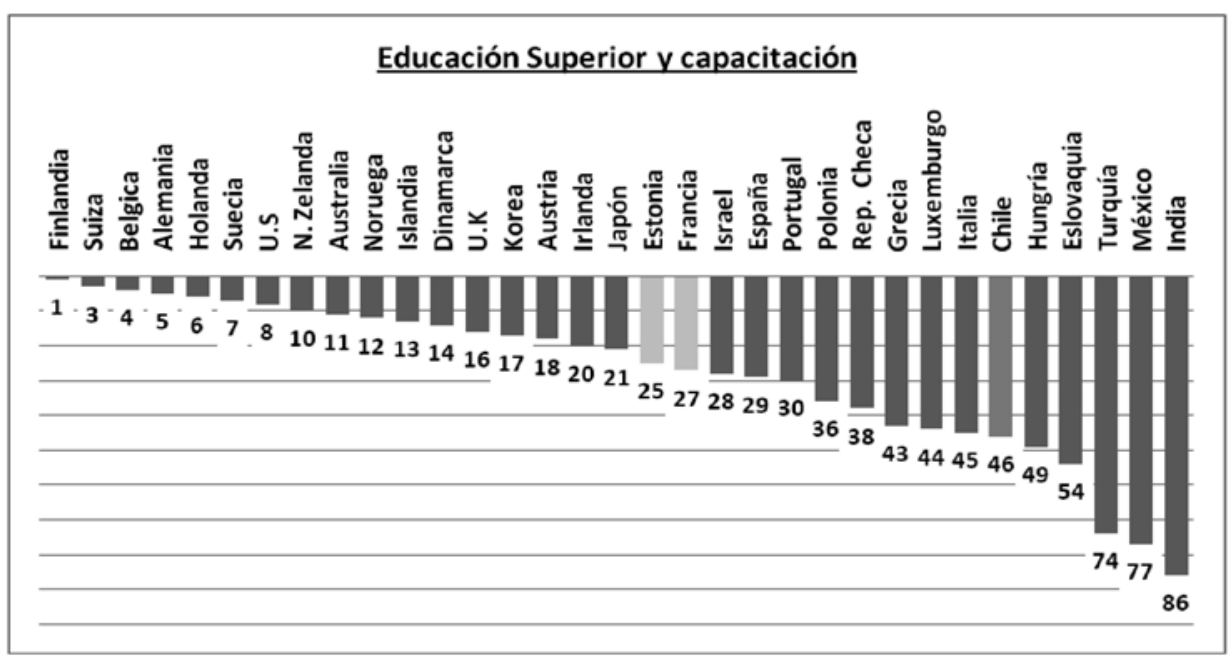

Fuente: Elaboración propia, a partir de la serie de datos del FEM. 
Gráfico $N^{\circ} 14$. Evolución en el periodo 2006-2012.

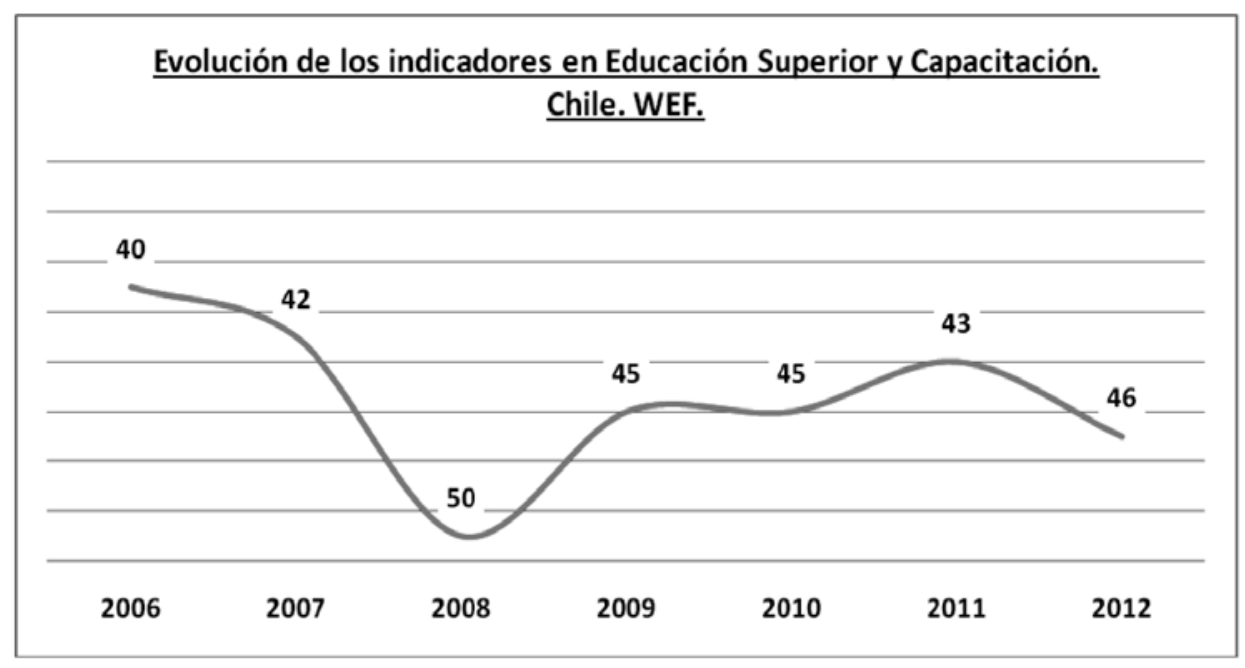

Fuente: Elaboración propia, a partir de la serie de datos del FEM.

\section{INNOVACIÓN}

En cuanto a innovación, el país también presenta retrasos, que lo sitúan en una situación muy desmejorada respecto del mundo OCDE, pronosticando escaso potencial de crecimiento con mayor contenido de valor agregado y mayor productividad. Como se dijo, la innovación es importante cuando se aplica en el contexto de una mejor utilización de los recursos existentes para lograr más óptimos resultados, especialmente cuando se trata de la calidad en materia de educación y salud. O sea, la innovación podría permitir elevar la calidad en estos ámbitos. 
Luis A. Riveros y Gustavo A, BÁez • Chile y la OCDE. Dicotomía entre lo...

Gráfico $N^{\circ}$ 15. Chile-OCDE: innovación.

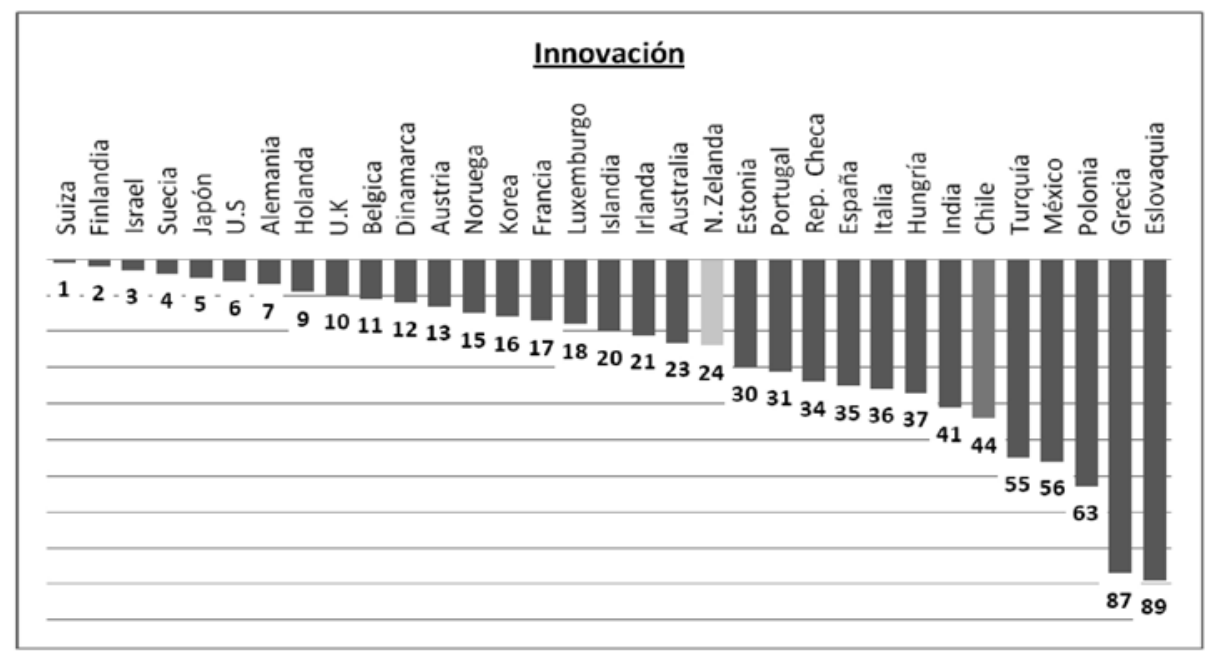

Fuente: Elaboración propia, a partir de la serie de datos del FEM.

El indicador sobre innovación (Gráfico 15) se compone de los siguientes factores: capacidad para innovar, calidad de las instituciones que realizan investigación científica, gasto privado de las compañías en $\mathrm{I}+\mathrm{D}$, colaboración entre Universidad e Industria en el desarrollo de I+D, estímulo del gobierno en el desarrollo de productos tecnológicos avanzados, disponibilidad de científicos e ingenieros, producción de patentes. La innovación es el resultado de la producción de nuevo conocimiento, tanto tecnológico como no tecnológico. Las innovaciones no tecnológicas se relacionan estrechamente con el "know how", el desarrollo de habilidades y condiciones de trabajo que están internalizadas y consolidadas tanto en la estructura productiva como en la cultura de las organizaciones.

Históricamente los avances tecnológicos han generado aumentos de la productividad y esta relación es observable tanto en la revolución industrial como en la reciente revolución digital. Para lograr este salto de la competitividad las economías deben conjugar un conjunto de factores para prepararlo. En lo relativo a la capacidad de innovación Chile aparece en el lugar $\mathrm{N}^{\circ} 66$, en virtud del retraso observado en los factores de base anteriormente revisados, mostrando una posición rezagada respecto del promedio de los países OCDE (Gráfico No 16). 
Gráfico $N^{o}$ 16. Chile-OCDE: Capacidad de innovación.

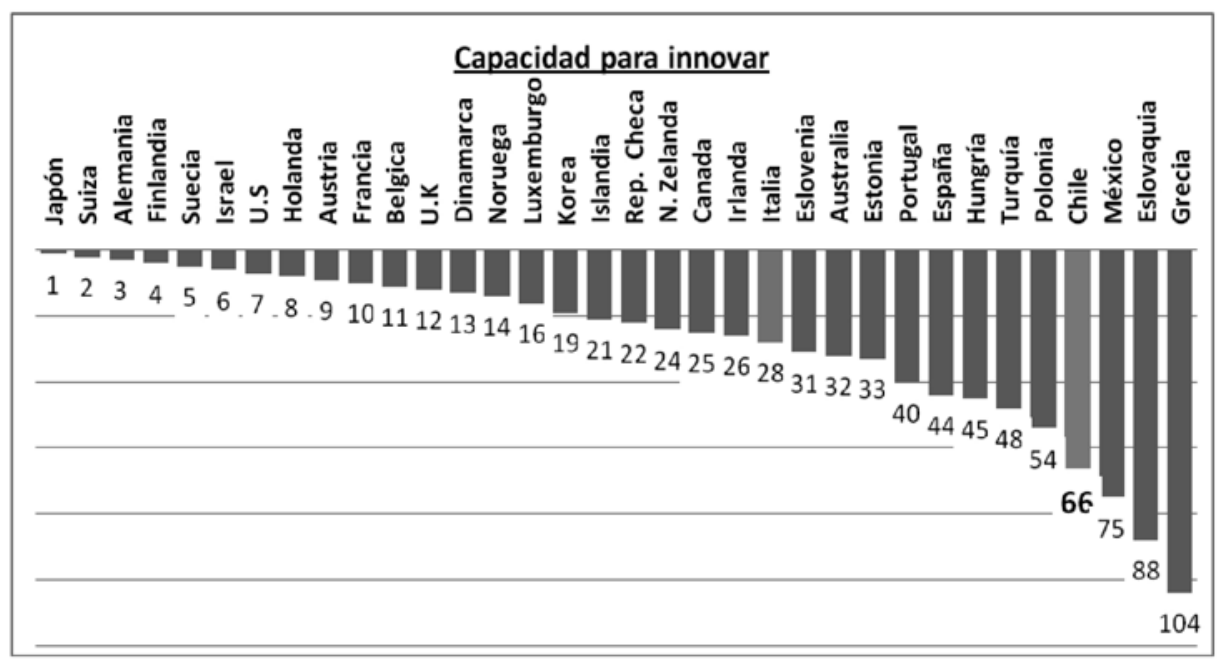

Fuente: Elaboración propia, a partir de la serie de datos del FEM.

La innovación no solo transforma la forma de hacer las cosas, sino que abre un amplio rango de nuevas posibilidades. La generación de conocimiento aumenta la posibilidad de generar mayor valor a nuestros sistemas productivos y resulta particularmente importante para los países que aspiran al desarrollo, tal como es el caso de Chile. Si cruzamos el dato anterior con la calidad de las instituciones que realizan investigación en los países OCDE, encontramos que Chile ocupa el lugar 51 , lo que revela nuevamente un retraso en este indicador, como lo muestra el gráfico $\mathrm{N}^{\circ} 17$. 
Luis A. Riveros y Gustavo A, BÁez • Chile y la OCDE. Dicotomía entre lo...

Gráfico No 17. Chile-OCDE: Calidad de la investigación.

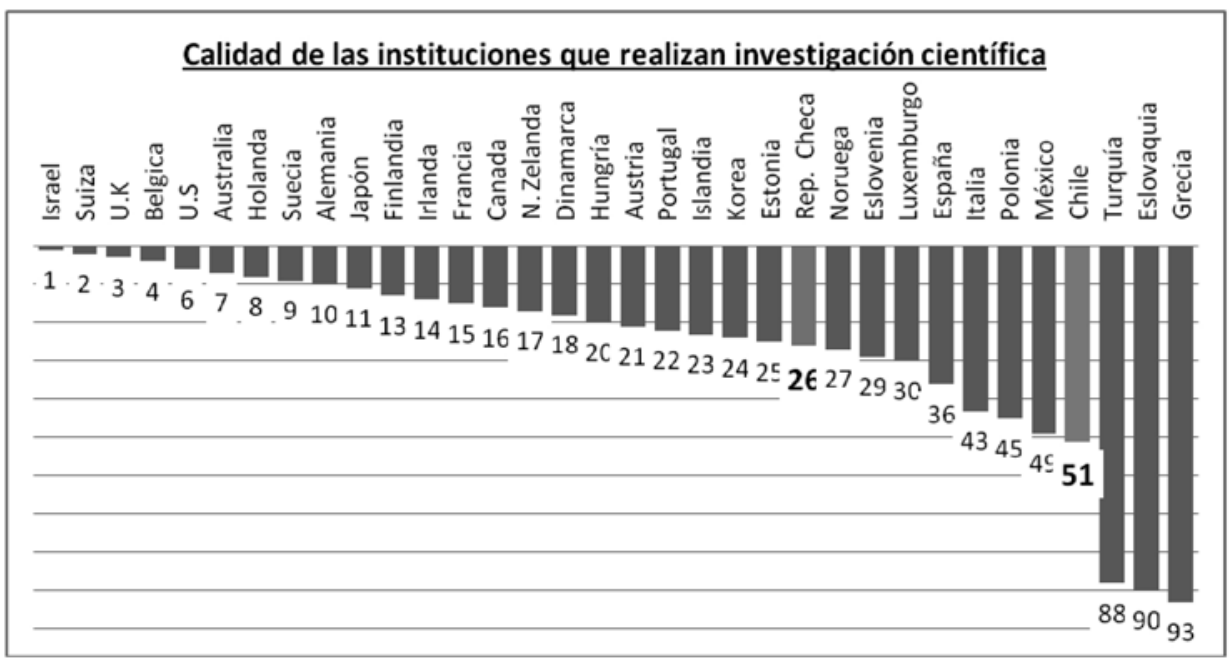

Fuente: Elaboración propia, a partir de la serie de datos del FEM.

El avance de una actividad virtuosa que nos conduzca a elevar el estándar de desempeño requiere de un ambiente y un contexto que favorezcan la innovación, estimulada tanto por el sector público como por el sector privado, mediante una adecuada ponderación de los factores involucrados en la función de desarrollo. Por su parte, la colaboración entre universidades e industria para el desarrollo de I+D resulta central, aspecto en que Chile ocupa el lugar $\mathrm{N}^{\circ} 44$ en el indicador, muy por debajo del promedio OCDE. 
Gráfico $N^{o}$ 18. Chile-OCDE: Colaboración Universidad-Industria en I+D.

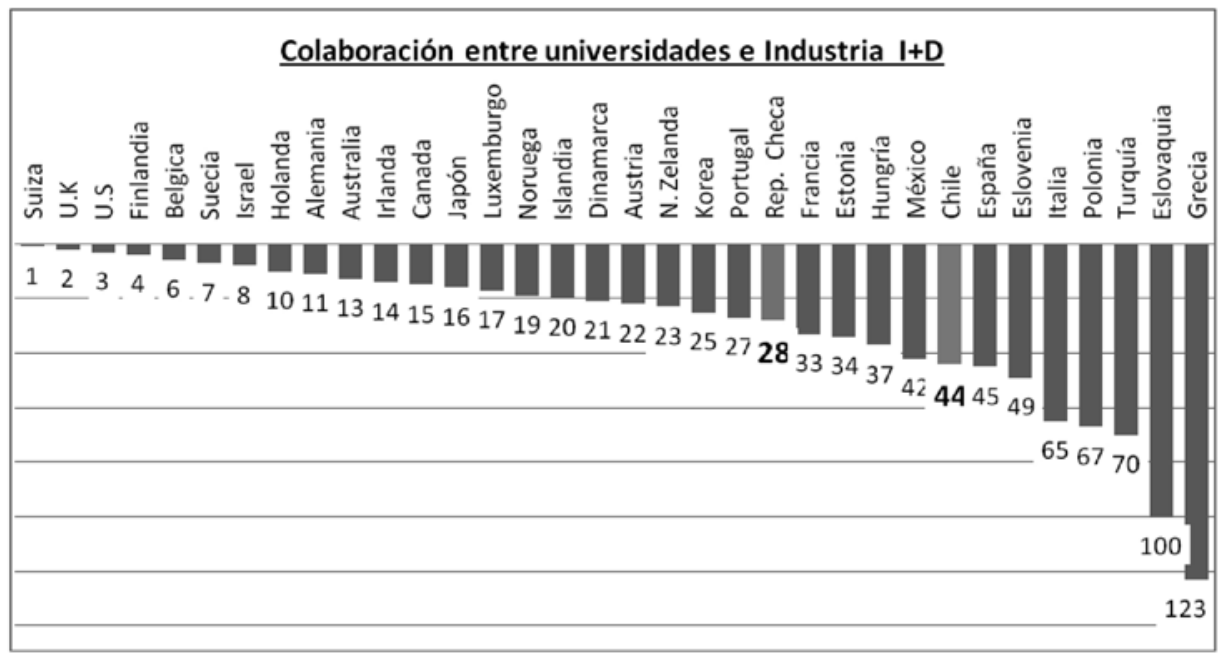

Fuente: Elaboración propia, a partir de la serie de datos del FEM.

oherentemente con el indicador an- en I+D nos situa en la posición $\mathrm{N}^{\circ} 60$ terior, el gasto privado de las compañias (gráfico $\mathrm{N}^{0} 19$ ).

Gráfico $N^{\circ}$ 19. Chile-OCDE: participación privada en $I+D$.

\section{Gasto privado de las compañias en Investigación y desarrollo}
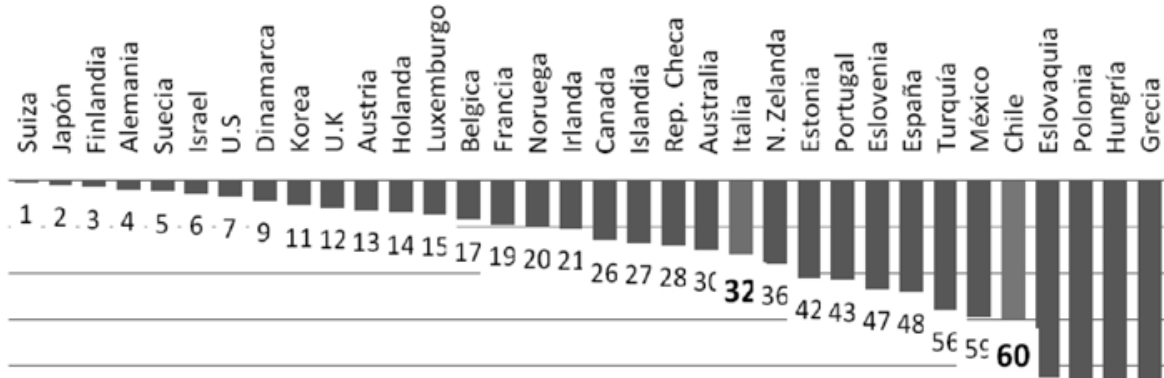

Fuente: Elaboración propia, a partir de la serie de datos del FEM. 
Luis A. Riveros y Gustavo A, BÁez • Chile y la OCDE. Dicotomía entre lo...

Gráfico $N^{\circ}$ 20. Chile-OCDE. Gobierno en producción de tecnología avanzada.

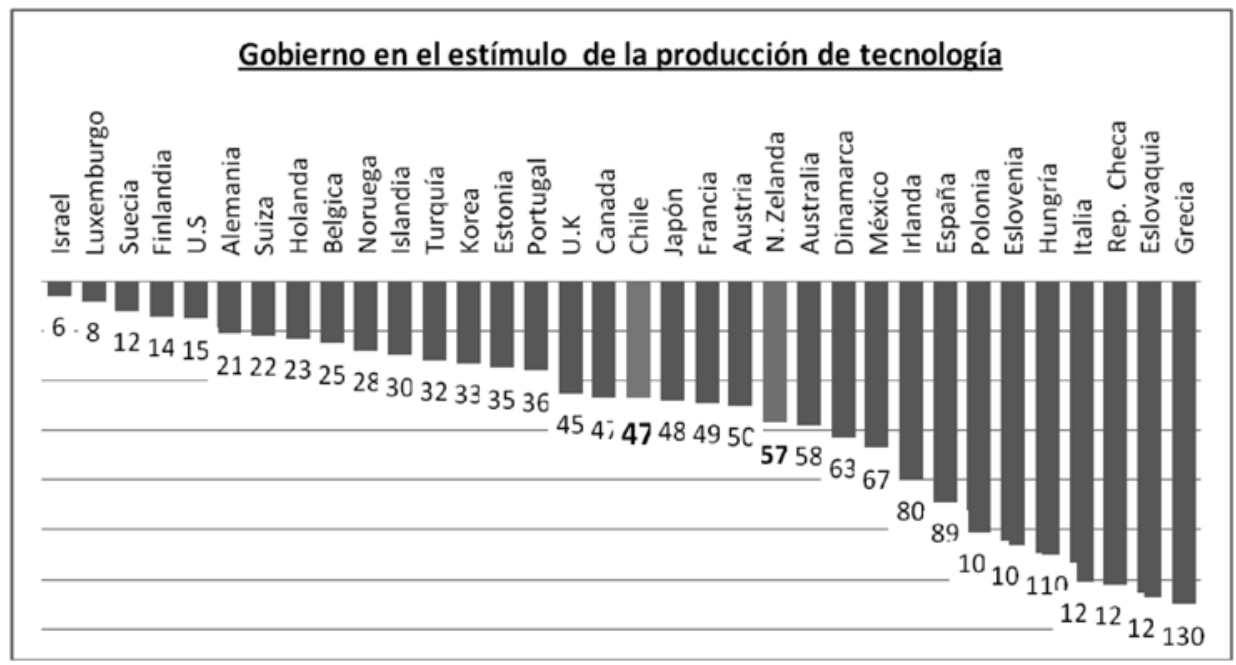

Fuente: Elaboración propia, a partir de la serie de datos del FEM.

No obstante todo lo anterior, la buena noticia la traen los indicadores relativos a la participación del gobierno en procurar el desarrollo de productos tecnológicos avanzados, indicador que muestra una posición relativa por encimasobre el promedio OCDE (Gráfico $\mathrm{N}^{\circ} 20$ ). De igual modo el indicador relativo a la disponibilidad de científicos e ingenieros muestra un desempeño por sobre el promedio de los paisese OCDE (Gráfico $\mathrm{N}^{\circ} 21$ ). Estos datos muestran la necesidad de fortalecer el desempeño privado en la generación de insituciones de alta calidad en el desarrollo de investigación científica, lo que puede generar una plataforma de conocimiento para construir nuevas tecnologías fortaleciendo la colaboración en investigación y desarrollo tecnológico entre las universidades y la industria en atención a la creciente competición en el acceso a las fuentes de capital y financiamiento en esta área. 
Gráfico $N^{\circ}$ 21. Chile-OCDE: disponibilidad de científicos e ingenieros.

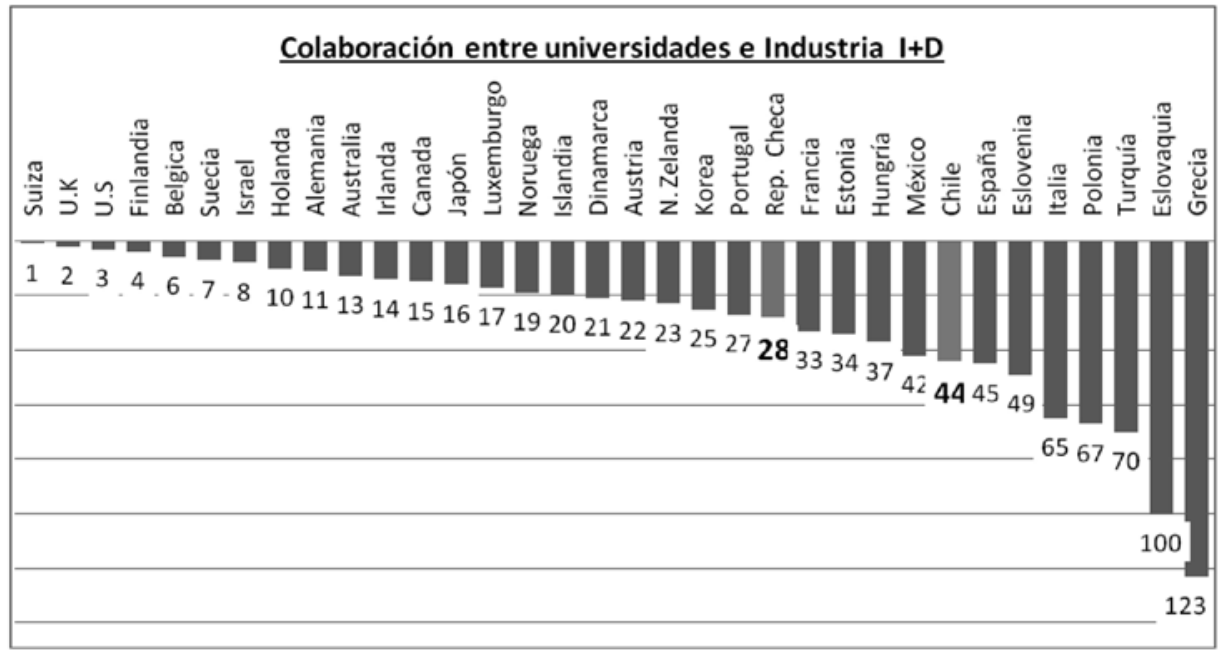

Fuente: Elaboración propia, a partir de la serie de datos del FEM.

Los datos reseñados sugieren que el Estado chileno debería reforzar la política de asignación de recursos para la investigación y asegurar la calidad formativa de ingenieros y científicos en la educación superior, cuidando de que existan vínculos de transmisión hacia el resto del sistema educacional y hacia la industria.

\section{Conclusiones}

La economía de Chile ha mostrado singular fortaleza desde la década de 1990. El establecimiento de una trayectoria de alto crecimiento, el aumento del ingreso per cápita, la inflación bien contenida y los excedentes presupuestarios han sido hechos recurrentes. Sin embargo, persiste una preocupante dicotomía entre los buenos resultados macroeconómicos y aquellos relativos a las variables humanas subyacentes, especialmente calidad de la educación y la salud, lo cual permite atribuir baja sustentabilidad a los resultados en materia de competitividad y estabilidad macroeconómicas.

Sin duda Chile converge hacia niveles más altos de vida y este fenómeno puede aumentar la demanda de coherencia entre el desempeño de nuestro sistema respecto de los objetivos de la convergencia económica y de la construcción de una sociedad más equitativa, en que la reducción de la pobreza se asocie a una mejor distribución del ingreso por medio del mejoramiento de la distribución de educación y salud y la obtención de mejores resultados educativos. Los 
Luis A. Riveros y Gustavo A, Báez • Chile y la OCDE. Dicotomía entre lo...

datos comparativos indican lo lejos que Chile está de la realidad OCDE en materia de desarrollo humano, y reseña la necesidad de mejores políticas. La innovación, junto con la investigación y desarrollo, es un factor importante para aumentar la productividad, pero también para disminuir la dicotomía existente entre lo macroeconómico y el desarrollo humano.

\section{BibliogRAFÍA}

Banco Central de Chile. Base de datos estadísticos. Diversas Ediciones

Education at a Glance. Indicators and analysis. Division of the OECD. Directorate for Education and Centre for International Research and Innovation. Andreas Schleicher, Etienne Albiser, Tracey Burns, Eric Charbonnier, Michael Davidson, Bo Hansson, Corinne Heckman, David Istance, Karinne Logez, Koji Miyamoto, Sophie Vayssettes, Patrick Werquin, Jean Yip. 2011.

The Global Competitiveness Index Report. Xavier Sala-i-Martin, chief advisor of the
Global Competitiveness Network. Klaus Schwab, Editor. World Economic Forum. Geneva. Switzerland. Serie de publicaciones 2001-2013.

Indicadores de la Educación: Chile en el contexto Internacional. Departamento de Estudios y Desarrollo. División de Planificación y Presupuesto. MINEDUC. Informes de Seguimiento de la ETP en el mundo. Organización de las Naciones Unidas para la Educación, la Ciencia y la Cultura. Ediciones UNESCO.

\section{Centros de Investigación} consultados.

- OECD Economic Surveys, disponibles en www.oecd.org/eco/surveys/chile, www. oecd.org/eco/Economic_Outlook.

- Economic Policy Reforms: Going for Growth. Disponibles en www.oecd.org/ economics/goingforgrowth.

- Foro Nacional de calidad de la educación para todos.

- Agencia Española de Cooperación Internacional para el Desarrollo, FRESCEAECID.

- CIDOB

- World Economic Forum 


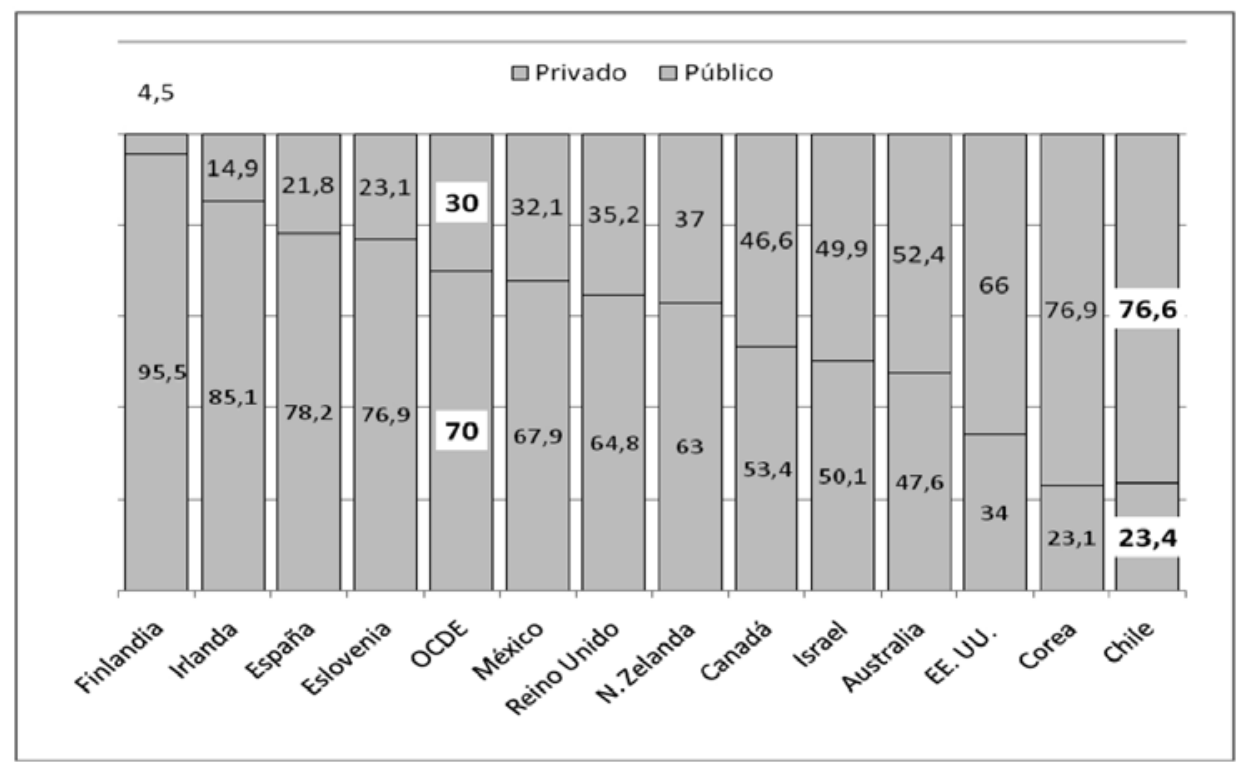

Fuente: Education at a Glance. Indicators and analysis. Division of the OECD. Directorate for Education and Centre for International Research and Innovation. Andreas Schleicher, Etienne Albiser, Tracey Burns, Eric Charbonnier, Michael Davidson, Bo Hansson, Corinne Heckman, David Istance, Karinne Logez, Koji Miyamoto, Sophie Vayssettes,

Patrick Werquin, Jean Yip. 2011.

Indicadores Cobertura y Gasto en Educación

\begin{tabular}{|l|l|l|}
\hline Ed. secundaria & Chile & OCDE \\
\hline $25-64$ años & $71 \%$ & $74 \%$ \\
\hline $25-34$ años & $87 \%$ & $82 \%$ \\
\hline Ed. Superior & Chile & OCDE \\
\hline $55-64$ años & $19 \%$ & $23 \%$ \\
\hline $25-34$ años & $38 \%$ & $38 \%$ \\
\hline Gasto por estudiante (Usd) & Chile & OCDE \\
\hline Primaria & 2.981 & 7.719 \\
\hline Secundaria & 2.892 & 9.312 \\
\hline Terciaria & 6.863 & 13.728 \\
\hline Porcentaje de gasto privado (\% PIB) & Chile & OCDE \\
\hline Ed. terciaria & $76,6 \%$ & $30 \%$ \\
\hline
\end{tabular}

Fuente: Education at a Glance. Op. Cit. 